\title{
Serum Magnesium Concentrations and All-cause, Cardiovascular, and Cancer Mortality among U.S. Adults: Results from The NHANES I Epidemiologic Follow-up Study
}

Xi Zhang, ${ }^{1}$ Jin Xia, ${ }^{2}$ Liana C. Del Gobbo, ${ }^{3}$ Adela Hruby, ${ }^{4}$ Qi Dai, ${ }^{5}$ Yiqing Song ${ }^{2}$

\section{Affiliations:}

1. Clinical Research Unit, Xinhua Hospital Affiliated to Shanghai Jiaotong University School of Medicine, Shanghai, China.

2. Department of Epidemiology, Richard M. Fairbanks School of Public Health, Indiana University, Indianapolis, IN, USA.

3. Department of Medicine, Division of Cardiovascular Medicine, Stanford University, Stanford, CA, USA.

4. Nutritional Epidemiology, Jean Mayer USDA Human Nutrition Research Center on Aging, Tufts University, Boston, MA, USA.

5. Department of Medicine, School of Medicine, Vanderbilt Ingram Cancer Center, Vanderbilt University Medical Center, Vanderbilt University, Nashville, Tennessee, USA

Authors' last names: Zhang X, Xia J, Del Gobbo LC, Hruby A, Song Y

Correspondence to Yiqing Song, MD, ScD, Department of Epidemiology, Richard M.

Fairbanks School of Public Health, Indiana University.

1050 Wishard Blvd, RG 5116, Indianapolis, IN, 46202-2872

Tel: 317-274-3833; Fax: 317-274-3443; E-mail: yiqsong@iu.edu

Short title: Magnesium and mortality in US adults

This is the author's manuscript of the article published in final edited form as:

Zhang, X., Xia, J., Del Gobbo, L. C., Hruby, A., Dai, Q., \& Song, Y. (2017). Serum magnesium concentrations and all-cause, cardiovascular, and cancer mortality among U.S. adults: Results from the NHANES I Epidemiologic Follow-up Study.

Clinical Nutrition. https://doi.org/10.1016/j.clnu.2017.08.021 


\title{
Foundation
}

The project described was supported by the Indiana University Health-Indiana University

School of Medicine Strategic Research Initiative (Drs. X Zhang, L Del Gobbo, and Y Song).

\begin{abstract}
Abbreviations:
Mg: magnesium; CVD: cardiovascular disease; NHANES I: National Health and Nutrition Examination Survey I; NHEFS: National Health and Nutrition Examination Survey I Epidemiologic Follow-up Study; CHD: congenital heart disease; ICD: International Classification of Diseases; CHD: congenital heart disease; HR: hazard ratio; CI: confidence interval.
\end{abstract}

Word count: 6,797; Tables: 3; Figure: 4; Reference: 58 


\section{ABSTRACT}

Background: Few studies have examined the associations of serum magnesium (Mg) concentrations with total and cause-specific mortality in a nationally representative sample of US adults. We investigate the dose-response relationships of baseline serum $\mathrm{Mg}$ concentrations with risk of mortalities in a large, nationally representative sample of US adults.

Methods: We analyzed prospective data of 14,353 participants aged 25-74 years with measures of serum Mg concentrations at baseline (1971-1975) from the National Health and Nutrition Examination Survey I Epidemiologic Follow-up Study (NHEFS). Mortality data was linked through December 31, 2011. We estimated the mortality hazard ratios (HRs), for participants within serum Mg categories of $<0.7,0.7-0.74,0.75-0.79,0.8-0.89$ (referent), 0.9-0.94, 0.95-0.99, and $\geq 1.0 \mathrm{mmol} / \mathrm{L}$ using weighted multivariate-adjusted Cox proportional hazards models.

Results: During a median follow-up of 28.6 years, 9,012 deaths occurred, including 3,959 CVD deaths, 1,923 cancer deaths, and 708 stroke deaths. The multivariate-adjusted HRs (95\% CIs) of all-cause mortality across increasing categories of Mg were 1.34 (1.02, 1.77), $0.94(0.75,1.18)$, 1.08 (0.97, 1.19), 1.00 (referent), 1.05 (0.95, 1.16), 0.96 (0.79, 1.15), and 0.98 (0.76, 1.26). Similar trends were observed for cancer (HRs for serum $\mathrm{Mg}<0.7$ : $1.39,95 \% \mathrm{CI}: 0.83,2.32$ ) and CVD mortality (HRs for serum Mg <0.7: 1.28, 95\% CI: 0.81, 2.02) but were not statistically significant. An elevated risk for stroke mortality was observed among participants with serum $\mathrm{Mg}<0.70 \mathrm{mmol} / \mathrm{L}$ (HR: 2.55, 95\% CI: 1.18, 5.48).

Conclusions: Very low serum Mg concentrations were significantly associated with an increased risk of all-cause mortality in US adults.

Keywords: serum Mg, Mg deficiency, all-cause mortality, CVD mortality, cancer mortality, stroke mortality 


\section{INTRODUCTION}

As a cofactor in hundreds of enzymatic reactions in the human body ${ }^{1}$, magnesium $(\mathrm{Mg})$ plays a significant role in multiple biological systems. Low Mg level has been associated with increased risk of chronic diseases in prospective studies, including cardiovascular disease (CVD) 2, 3 , type 2 diabetes ${ }^{4-8}$, metabolic related diseases ${ }^{9,10}$, and colorectal cancer ${ }^{11}$. Mechanistic evidence supports a role for magnesium in cardiovascular diseases, including on blood pressure ${ }^{12}$, oxidative stress ${ }^{13}$, endothelial function ${ }^{14}$ and thrombosis ${ }^{15}$, and arrhythmia ${ }^{16}$. Additionally, Mg supplementation may improve glucose induced insulin response and insulin-mediated glucose disposal among nondiabetic participants ${ }^{17,18}$

Although multiple lines of evidence support a role of Mg in major chronic diseases, few longitudinal studies have examined the relationship between serum Mg and mortality. One study, based on data from NHANES I Follow-up Study 1971-75, examined the effects of serum Mg on risk of CVD and all-cause mortality and observed an inverse association between serum Mg and mortality from all cause and CVD in participants followed up through $1992{ }^{19}$. Recently, the NHANES I mortality follow-up has been extended to include deaths events through a longerterm follow-up period, providing more than double the number of mortality cases $(n=9012)$ to enable us to not only evaluate associations with all-cause mortality, but also cause-specific mortality, including cancer and stroke. We hypothesize that the population with low serum $\mathrm{Mg}$ levels have a high risk of mortality.

\section{METHODS}

\section{Study design and population}

We used data from the NHANES I 1971-1975, a multistage national probability survey, 
designed to evaluate the health and nutritional status of US general population ${ }^{20}$. Among the representative sample of 32,000 US civilians selected, 14,407 participants at NHANES I (aged 25-74 years) with complete medical examinations were included in a longitudinal follow-up study, NHEFS, in $1982{ }^{21}$. The baseline information for NHEFS, including demographic and socioeconomic information and physical and laboratory examinations, was provided by NHANES I. After excluding 54 participants with missing measures of serum Mg, we finally included a total of 14,353 participants in the analysis. The design of the NHANES has been reviewed and approved by Institutional Review Board at the Centers for Disease Control and Prevention. All subjects provided written informed consent.

\section{Outcome measures}

The NHEFS cohort study included four waves of follow-up periods in 1982-1984, 1986, 1987, and 1992. The follow-up data contained information on health-related outcomes. Vital status was assessed and confirmed by proxy interviews, medical records, and death certificate through the National Death Index. New record linkages of NHEFS participants to death records through December 31, 2011 were conducted by National Center for Health Statistics ${ }^{22,23}$. Our primary outcomes included all-cause, CVD, cancer, and stroke mortality. Causes of mortality were divided into four categories using the Tenth Version of the International Classification of Diseases (ICD-10): cancer (C00-97), CVD (I00-78), ischemic heart disease (CHD) (I58-63), and stroke (I60-69) deaths.

\section{Baseline Mg measurements}

Non-fasting blood samples were collected and frozen and then sent to the Centers for Disease Control and Prevention for biochemical assays. Serum Mg concentrations were determined during the baseline survey by atomic absorption spectrophotometry using the method 
of Hansen and Freier ${ }^{24}$. Quality control samples were analyzed with every 20 specimens, and the repeat limits were below 1.40 and above $2.10 \mathrm{mEq} / \mathrm{L}^{25,26}$. We converted the unit of “mEq/L” for serum Mg concentrations into “mmol/L” for this study.

\section{Confounders}

Covariates were measured at baseline, including age, sex, race, body mass index (BMI) $\left(\mathrm{kg} / \mathrm{m}^{2}\right)$, education ( $\geq$ high school degree, or $<$ high school degree), alcohol intake ( $>2$ times per week, or $<2$ times per week), levels of recreational and non-recreational physical activity (selfreport of being very active, moderately active, or quite inactive), smoking (never, former current), sitting blood pressure (mmHg), history of diabetes (self-reported physician diagnosed diabetes, or use of hypoglycemic medication), history of hypertension (self-reported physician diagnosis, or taking antihypertensive drugs), history of CVD (self-reported physician diagnosed heart failure, heart attack, stroke, or possible heart or circulatory troubles), serum calcium and cholesterol levels, and intake of vitamin or mineral supplements (self-reported any vitamin or mineral supplementation within last 30 days before the interview).

\section{Statistical analysis}

We estimated the hazard ratios (HRs) and 95\% confidence intervals (CIs) of mortality for categories of serum Mg comparing to the reference group (0.80-0.89 mmol/L) using Cox proportional hazards models. Weights accounting for the complex sampling design of the survey were applied in Cox proportional hazards model. Age, sex, race, BMI, education, cigarette smoking status, alcohol consumption, physical activity, history of hypertension, history of diabetes, and use of vitamin and/or mineral supplements were included as covariates in the models.

In order to explore the possible dose-response relationship between serum Mg levels and 
all-cause and cause-specific mortality, we fitted restricted cubic spline regression models with four knots at $0.73,0.82,0.87$, and $0.96 \mathrm{mmol} / \mathrm{L}$.

Finally, pre-specified subgroup analyses and sensitivity analyses were also performed to explore potential effect modifications or assess the robustness of the results. The subgroup variables included age ( $<65 \mathrm{yr}$ or $\geq 65 \mathrm{yr}$ ), sex (men or women), race (white, black, or other), BMI ( $<25 \mathrm{~kg} / \mathrm{m}^{2}$ or $\geq 25 \mathrm{~kg} / \mathrm{m}^{2}$ ), recreational physical activity (very active, moderately active, or quite inactive), non-recreational physical activity (very active, moderately active, or quite inactive), diabetes (yes or no), hypertension (yes or no), CVD (yes or no), cigarette smoking status (current smoker or non-smoker), alcohol consumption (current drinker or non-drinker), and use vitamin and/or mineral supplements (user or non-user). We also conducted survey logistic regression models adjusted for the above mentioned covariates to identify the variable(s) that independently predicted low serum $\mathrm{Mg}(<0.70 \mathrm{mmol} / \mathrm{L})$. Low serum $\mathrm{Mg}$ was defined as serum $\mathrm{Mg}<0.75 \mathrm{mmol} / \mathrm{L}$, according to the normal reference range for serum $\mathrm{Mg}$ (33); and a very low level of serum $\mathrm{Mg}$ was defined as serum $\mathrm{Mg}<0.70$, according to the clinical cut-off for hypomagnesemia. We performed the interaction analyses testing low serum Mg associations with all-cause mortality, CVD mortality, cancer mortality, and stroke mortality in different population characteristics and health status mentioned above. Sensitivity analyses were conducted among participants without prevalent diabetes, hypertension, or CVD at baseline or by further adjustment for dietary potassium and calcium levels, as well as serum calcium concentrations.

All statistical analyses were conducted by using SUDAN and SAS software (version 9.4; SAS Institute). For all analyses, $\mathrm{P}<0.05$ for 2-tailed tests was considered statistically significant. 


\section{RESULTS}

\section{Baseline Characteristics and Distribution of Serum Mg Concentrations}

In the 1971-1975 NHANES I data set, a total of 14,353 participants aged 25-74 years had measures of serum Mg. Serum Mg concentrations were relatively normally distributed among all participants (Figure 1A) with a mean of 0.85 (SE: 0.02) mmol/L. The mean serum Mg concentrations were $0.02 \mathrm{mmol} / \mathrm{L}$ higher in men than women and $0.02 \mathrm{mmol} / \mathrm{L}$ higher in whites than blacks (all $P$-values < 0.001) (Figure 1B \& 1C). Nearly 4\% of men and 7\% of women had serum Mg less than $0.75 \mathrm{mmol} / \mathrm{L}$; serum Mg levels were extremely low $(<0.70 \mathrm{mmol} / \mathrm{L})$ among $1 \%$ of men and $2 \%$ of women. Participants with low serum Mg generally tended to be older, overweight, less educated, smoke, consume alcohol, have high blood pressure, or had lower family income (TABLE 1). After adjusted for potential confounders, women, non-white participants, current smokers, vitamin/mineral supplement users, or participants with diabetes, hypertension, or low levels of total cholesterol were more likely to have low serum Mg, respectively (TABLE 2).

\section{All-cause mortality}

During a median 28.6 years of follow-up, a total of 9,012 deaths (63\%) among 14,353 participants occurred. Among the 9,012 deaths, 3,959 (42\%) were due to CVD, 1,923 (23\%) due to cancer, and 708 (7\%) due to stroke. Of stroke deaths, 542 (72\%) died from ischemic stroke, 125 (21\%) from cerebral stroke, and 41 (7\%) from other stroke. The mean age at death was 75 years and the mean baseline serum Mg levels before death was $0.85 \mathrm{mmol} / \mathrm{L}$. Nearly $50 \%$ of all deaths occurred in women, 29\% were hypertensive participants, $6 \%$ had diabetes mellitus, and $14 \%$ had CVD. 
By category of increasing serum $\mathrm{Mg}<0.7,0.7-0.74,0.75-0.79,0.8-0.89,0.9-0.94,0.95-$ $0.99, \geq 1.0 \mathrm{mmol} / \mathrm{L}$, the corresponding all-cause mortality rates were $3343,1955,1959,1999$, 2230, 2259, 2307 per 100,000 person-years, respectively. Compared to the reference group (serum Mg of 0.8-0.89 mmol/L), the multivariable-adjusted risk of all-cause mortality for each group in ascending order was 1.34 (95\% CI: 1.02, 1.77), $0.94(0.75,1.18), 1.08(0.97,1.19), 1.05$ (0.95, 1.16), $0.96(0.79,1.15)$, and 0.98 (0.76, 1.26), respectively (TABLE 3). An L-shaped curve was shown between serum Mg and all-cause mortality after adjusting for potential confounders (FIGURE 2). We did not detect any significant association between serum Mg levels and mortality after serum $\mathrm{Mg}$ levels reached $0.70 \mathrm{mmol} / \mathrm{L}$.

\section{Cause-specific mortality}

After adjustment of age, sex, and race, participants with serum Mg levels $<0.70 \mathrm{mmol} / \mathrm{L}$ had a 57\% and 58\% higher risk of CVD and CHD mortality comparing to those with serum Mg levels of 08-0.89 mmol/L. However, these associations were not statistically significant after further adjusting for history of diabetes and hypertension (TABLE 2). The results of multivariate analysis showed participants with extremely low levels of serum $\mathrm{Mg}<0.70 \mathrm{mmol} / \mathrm{L}$ had a high risk of stroke mortality compared with the reference group (HR: 2.55; 95\% CI: 1.18, 5.48). Among subtypes of stroke including cerebral stroke, ischemic stroke, and other stroke, only risk of ischemic stroke was significantly high among participants with serum Mg lower than 0.7 mmol/L (HR, 3.6; 95\% CI: 1.56, 8.33). There was a 23\% elevation in risk of cancer mortality (HR: 1.23; 95\% CI: 1.01, 1.50) among those with a slightly higher level of Mg (0.9-0.95 $\mathrm{mmol} / \mathrm{L}$ ) than 0.8-0.89 $\mathrm{mmol} / \mathrm{L}$.

\section{Subgroup and sensitivity analysis}

We found that an inverse association between risks of all-cause and CVD mortality and 
levels of Mg was significant only in men; HRs were 6.87 (95\% CI: 2.18, 21.68) for all-cause mortality and 2.47 (95\% CI: 1.31, 4.67) for CVD mortality, respectively (FIGURE 3). The significant associations with all-cause and cancer mortality were observed only in blacks with HR of 2.07 (95\% CI: 1.45, 2.95) for all-cause mortality and HR of 2.99 (95\% CI: 1.39, 6.43) for cancer mortality, but not in whites with HR of $1.16(95 \% \mathrm{CI}$ : 0.831 .63 ; P-interaction $=0.02)$ for all-cause mortality and HR of 0.92 (95\% CI: 0.37, 2.27; $P$-interaction $=0.08)$ for cancer mortality (FIGURE 4). Current smokers with low serum Mg levels had higher risks of all-cause mortality (HR: 1.94; 95\% CI: 1.48, 2.54) than those nonsmokers (HR: 1.04; 95\% CI: 0.71, 1.53; $P$-interaction $=0.01$ ). No significant interactions were observed between $\mathrm{Mg}$ and the following covariates: age, BMI, physical activity level, alcohol consumption, CVD, hypertension, and diabetes.

To evaluate the robustness of the results, we included dietary potassium and calcium levels and serum calcium concentrations in the adjusted model and found no changes in the associations between low levels of Mg and all-cause, CVD, and cancer mortality. When participants with diabetes mellitus, hypertension, or CVD were excluded, the association between low levels of Mg and all-cause mortality became stronger (HR: 2.00; 95\% CI: 1.34, 2.97). However, further adjustment of dietary factors attenuated the significant association of low serum Mg with stroke mortality risk. Excluding patients with diabetes mellitus, hypertension, or CVD drove the association between high serum Mg and risk of cancer mortality towards the null.

\section{DISCUSSION}

In this large nationally representative sample of US adults with an average of 28 years of followup, we observed that very low serum Mg concentrations $(<0.70 \mathrm{mmol} / \mathrm{L})$ were significantly 
associated with all-cause mortality. Although similar trends were observed for cancer and CVD mortality, they did not reach statistical significance. Additionally, there was suggestive evidence that serum $\mathrm{Mg}<0.70 \mathrm{mmol} / \mathrm{L}$ was associated with increased risks of mortality due to total stroke or ischemic stroke. Our findings support the hypothesis that very low serum Mg may be clinically useful for predicting mortality and other long-term health outcomes in the general population.

The serum Mg threshold we identified in US adults refines the associations between serum Mg concentrations and long-term health outcomes. Only few studies have evaluated the threshold of serum Mg to mortality or CVD risk. Several studies among patients receiving hemodialysis investigated the threshold effect of serum Mg levels on mortality and suggested a higher cut-off point of serum $\mathrm{Mg}$ (>0.95 mmol/L) for predicting mortality ${ }^{27-29}$. However, $\mathrm{Mg}$ homeostasis among kidney diseases patients differs from healthy individuals; therefore, these findings are of limited relevance to the general population. Moreover, previous NHANES studies examining the association of serum Mg and mortality used a reference value of $<0.8 \mathrm{mmol} / \mathrm{L}$, potentially obscuring the association of elevated mortality risk only present at the lower concentrations $(<0.7 \mathrm{mmol} / \mathrm{L})$ we observed in our study ${ }^{19}$.

Several mechanisms may explain the beneficial effects of Mg, including maintaining glucose and insulin homeostasis ${ }^{30,31}$, improving lipid metabolism ${ }^{32-35}$, enhancing the vascular or myocardial contractility ${ }^{36-38}$ and vasodilation ${ }^{36,38-40}$, providing anti-arrhythmic ${ }^{41,42}$ and antiplatelet effects ${ }^{37,39,43,44}$. Moreover, several small secondary prevention randomized trials have shown that oral Mg supplementation improved endothelial function ${ }^{14}$, reduced thrombosis ${ }^{15}$, increased cardiopulmonary function and left ventricular ejection fraction index ${ }^{45}$ of CVD patients. Mg deficiency may increase the risk of various cardiac events and cardiac death ${ }^{46-48}$. 
Although we did not observe the Mg-cancer mortality association in this study, several evidence indicated that metabolic disorders induced by Mg deficiency might be risk factors of colorectal and pancreatic cancer ${ }^{11}$. Previous animal studies and cell cultures suggest a role for $\mathrm{Mg}$ in carcinogenesis through its effects on cell proliferation, differentiation, apoptosis, and angiogenesis ${ }^{49}$ as well as innate immunity and inflammation ${ }^{50,51}$.

Previous observational studies have linked low Mg levels and chronic diseases ${ }^{2-8,11}$, which are major contributors to all-cause mortality and cause-specific mortality in the US. We found that there were decrease trends in both SBP/DBP levels and prevalence of diabetes and hypertension as serum Mg increased. And participants with hypertension or diabetes were more likely to be with $\mathrm{Mg}$ deficiency, the risk was twice higher than general population. To minimize residual confounding due to these diseases, we controlled for history of hypertension, diabetes mellitus, BMI, and vitamin/mineral supplements use in our multivariate model. Moreover, subgroup analyses stratifying by these factors were also conducted, but no significant interactions were detected. Although history of diabetes, CVD, and hypertension did not significantly modify the relation of serum Mg with mortality, the association was strengthened in the general population after excluding those with these diseases.

In this study, we observed an association of low serum Mg levels with all-cause and CVD mortality in men only. Meanwhile, the average Mg levels in men were $0.02 \mathrm{mmol} / \mathrm{L}$ higher than that in women. And the prevalence of $\mathrm{Mg}<0.70 \mathrm{mmol} / \mathrm{L}$ was $50 \%$ lower in men than in women in our study. Consistent with our findings, a pooled analysis of two large population-based cohort studies of Chinese adults showed that low circulating Mg levels were associated with to high risks of all-cause mortality and CHD mortality only in men ${ }^{52}$. An elevated risk for mortality with low Mg was also found in a cohort of 4,035 men aged 30-60 years in France ${ }^{53}$. 
Similarly, inverse association between circulating $\mathrm{Mg}$ and ischemic heart disease was only reported among studies with more male participants (percentage of male $\geq$ median) in a metaanalysis ${ }^{2}$. As a mechanism for potential between-gender differences in the pathophysiology of low serum $\mathrm{Mg}$ on disease risk is unclear, this finding may be due to chance. In any case, these findings warrant further study.

We also found that Mg deficiency was associated with a twice higher risk of all-cause mortality among smokers than non-smokers. These findings are consistent with risks from $\mathrm{Mg}$ deficiency among smokers reported in several epidemiological studies ${ }^{54-56}$. Poor Mg status, together with long-term exposure to thiocyanate anions among smokers, accelerates the atherosclerotic processes in animal models ${ }^{57}$. Moreover, a randomized clinical trial found that Mg deficiency accelerates the development of nicotine addiction through increasing the $\mathrm{Mg}$ dependent N-Methyl-D-aspartic acid or N-Methyl-D-aspartate receptors activity ${ }^{58}$. Our findings, combined with these studies, suggest that a possible interplay between low serum Mg and smoking might amplify the effects of each risk factor alone on disease risk.

Our study has several major strengths. Our use of NHANES data provided large nationally representative sample of the US adult population, increasing generalizability. The long follow-up and large number of cases ( $\mathrm{n}>9000$ ) in our study increased statistical power. While dietary Mg has some limitations due to collinearity with dietary potassium, and recall bias introduced by using food frequency questionnaire, both of these limitations do not apply to serum Mg. Our examination of cause-specific mortality, and dose-response relationships using splines, represents the largest and most in-depth examination of the association of serum $\mathrm{Mg}$ and mortality yet conducted.

Several limitations merit consideration. First, given the nature of the observational 
studies, we cannot draw conclusions on causal relations between serum Mg and mortality. Second, the influence of possible change in Mg status on mortality risk cannot be assessed in the lack of longitudinal measurements of serum Mg. This gap needs to be addressed in future studies. Finally, the possibility of residual confounding due to unmeasured/ poorly measured factors or time-varying factors cannot be excluded.

In conclusion, our results from a large, nationally representative, and prospective study indicated that baseline serum $\mathrm{Mg}$ at a low level of $<0.70 \mathrm{mmol} / \mathrm{L}$ was significantly associated with an increased risk of all-cause mortality in US adults over an average follow-up of 28 years. Our findings support the hypothesis that serum Mg may be clinically useful for predicting longterm health outcomes and mortality in the general population. 


\section{ACKNOWLEDGEMENT}

CONFLICT OF INTERESTS

None

\section{AUTHOR'S CONTRIBUTIONS}

The authors' contributions to manuscript were as follows - XZ and YS: designed and

conducted this study; XZ and JX: cleaned and analyzed data and had primary responsibility for the final content of the manuscript; and all authors, including XZ, YS, JX, LD, and AH wrote the manuscript, and read and approved the manuscript. 


\section{REFERENCES}

1. Sontia B and Touyz RM. Role of magnesium in hypertension. Archives of biochemistry and biophysics. 2007;458:33-9.

2. Del Gobbo LC, Imamura F, Wu JH, de Oliveira Otto MC, Chiuve SE and Mozaffarian D. Circulating and dietary magnesium and risk of cardiovascular disease: a systematic review and meta-analysis of prospective studies. The American journal of clinical nutrition. 2013;98:160-73.

3. Joosten MM, Gansevoort RT, Mukamal KJ, van der Harst P, Geleijnse JM, Feskens EJ, Navis G, Bakker SJ and Group PS. Urinary and plasma magnesium and risk of ischemic heart disease. The American journal of clinical nutrition. 2013;97:1299-306.

4. Song Y, He K, Levitan EB, Manson JE and Liu S. Effects of oral magnesium supplementation on glycaemic control in Type 2 diabetes: a meta-analysis of randomized double-blind controlled trials. Diabetic medicine : a journal of the British Diabetic Association. 2006;23:1050-6.

5. He K, Liu K, Daviglus ML, Morris SJ, Loria CM, Van Horn L, Jacobs DR, Jr. and Savage PJ. Magnesium intake and incidence of metabolic syndrome among young adults. Circulation. 2006;113:1675-82.

6. Ford ES, Li C, McGuire LC, Mokdad AH and Liu S. Intake of dietary magnesium and the prevalence of the metabolic syndrome among U.S. adults. Obesity. 2007;15:1139-46.

7. Guerrero-Romero F and Rodriguez-Moran M. Magnesium improves the beta-cell function to compensate variation of insulin sensitivity: double-blind, randomized clinical trial. European journal of clinical investigation. 2011;41:405-10.

8. Xu T, Chen GC, Zhai L and Ke KF. Nonlinear Reduction in Risk for Type 2 Diabetes by Magnesium Intake: An Updated Meta-Analysis of Prospective Cohort Studies. Biomedical and environmental sciences : BES. 2015;28:527-34.

9. Dibaba DT, Xun P, Fly AD, Yokota K and He K. Dietary magnesium intake and risk of metabolic syndrome: a meta-analysis. Diabetic medicine : a journal of the British Diabetic Association.

2014;31:1301-9.

10. Ju SY, Choi WS, Ock SM, Kim CM and Kim DH. Dietary magnesium intake and metabolic syndrome in the adult population: dose-response meta-analysis and meta-regression. Nutrients. 2014;6:6005-19.

11. Chen GC, Pang Z and Liu QF. Magnesium intake and risk of colorectal cancer: a meta-analysis of prospective studies. European journal of clinical nutrition. 2012;66:1182-6.

12. Iseri LT and French JH. Magnesium: nature's physiologic calcium blocker. American heart journal. 1984;108:188-93.

13. Dickens BF, Weglicki WB, Li YS and Mak IT. Magnesium deficiency in vitro enhances free radicalinduced intracellular oxidation and cytotoxicity in endothelial cells. FEBS Lett. 1992;311:187-91.

14. Shechter M, Sharir M, Labrador MJ, Forrester J, Silver B and Bairey Merz CN. Oral magnesium therapy improves endothelial function in patients with coronary artery disease. Circulation. 2000;102:2353-8.

15. Shechter M, Merz CN, Paul-Labrador M, Meisel SR, Rude RK, Molloy MD, Dwyer JH, Shah PK and Kaul S. Oral magnesium supplementation inhibits platelet-dependent thrombosis in patients with coronary artery disease. The American journal of cardiology. 1999;84:152-6.

16. Ganga HV, Noyes A, White CM and Kluger J. Magnesium adjunctive therapy in atrial arrhythmias. Pacing Clin Electrophysiol. 2013;36:1308-18.

17. Guerrero-Romero F, Tamez-Perez HE, Gonzalez-Gonzalez G, Salinas-Martinez AM, MontesVillarreal J, Trevino-Ortiz JH and Rodriguez-Moran M. Oral magnesium supplementation improves insulin 
sensitivity in non-diabetic subjects with insulin resistance. A double-blind placebo-controlled randomized trial. Diabetes Metab. 2004;30:253-8.

18. Paolisso G, Sgambato S, Gambardella A, Pizza G, Tesauro P, Varricchio M and D'Onofrio F. Daily magnesium supplements improve glucose handling in elderly subjects. The American journal of clinical nutrition. 1992;55:1161-7.

19. Ford ES. Serum magnesium and ischaemic heart disease: findings from a national sample of US adults. International Journal of Epidemiology. 1999;28:645-651.

20. Miller HW. Plan and operation of the health and nutrition examination survey. United states-1971-1973. Vital Health Stat 1. 1973:1-46.

21. Cohen BB, Barbano HE, Cox CS, Feldman JJ, Finucane FF, Kleinman JC and Madans JH. Plan and operation of the NHANES I Epidemiologic Followup Study: 1982-84. Vital Health Stat 1. 1987:1-142.

22. Christine S. Cox MEM, Sandra T. Rothwell, Madelyn A. Lane, Cordell D. Golden, Jennifer H. Madans, Jacob J. Feldman, Offıce of Analysis, Epidemiology, and Health Promotion. Plan and Operation of the NHANES I Epidemiologic Followup Study, 1992. Vital Health Statistics report, Series 1, No 35 Hyattsville, MD: National Center for Health Statistics. 1997:1-231.

23. Statistics NCFH. NCHS 2011 Linked Mortality Files Matching Methodology. http://wwwcdcgov/nchs/data/datalinkage/2011 linked mortality file matching methodologypdf. 2011.

24. Hansen JL and Freier EF. The measurement of serum magnesium by atomic absorption spectrophotometry. Am J Med Technol. 1967;33:158-66.

25. Statistics NCfH. NHANES I hematology and clinical chemistry procedures developed and utilized by the center for disease control, Bureau of Laboratories, 1971-1975. Washington, DC: US Government Printing Office. 1979.

26. National Center for Health Statistics. Biochemistry, Serology, Hematology, Blood Slides, Urine Dipst. National Health and Nutrition Examination Survey, 1971-75. Hyattsville, Maryland: National Center for Health Statistics. 1991.

27. Kurita N, Akizawa T, Fukagawa M, Onishi Y, Kurokawa K and Fukuhara S. Contribution of dysregulated serum magnesium to mortality in hemodialysis patients with secondary hyperparathyroidism: a 3-year cohort study. Clin Kidney J. 2015;8:744-52.

28. Sakaguchi Y, Fujii N, Shoji T, Hayashi T, Rakugi H, Iseki K, Tsubakihara Y, Isaka Y and Committee of Renal Data Registry of the Japanese Society for Dialysis T. Magnesium modifies the cardiovascular mortality risk associated with hyperphosphatemia in patients undergoing hemodialysis: a cohort study. PloS one. 2014;9:e116273.

29. Joao Matias P, Azevedo A, Laranjinha I, Navarro D, Mendes M, Ferreira C, Amaral T, Jorge C, Aires I, Gil C and Ferreira A. Lower serum magnesium is associated with cardiovascular risk factors and mortality in haemodialysis patients. Blood purification. 2014;38:244-52.

30. Nadler JL, Buchanan T, Natarajan R, Antomipillai I, Bergman R and Rude R. Magnesium deficiency produces insulin resistance and increased thromboxan synthesis. Hypertension. 1993;21:1024-1029.

31. Paolisso $G$ and Ravusin E. Intracellular magnesium and insulin resistance: results in Pima Indians and Caucasians. J Clin Endocrinol Metab. 1995;80:1382-1385.

32. Altura BT, Brust M, Bloom S, Barbour RL, Stempak JG and Altura BM. Magnesium dietary intake modulates blood lipid levels and atherogenesis. Proc Natl Acad Sci U S A. 1990;87:1840-4.

33. Davis WH, Leary WP, Reyes AJ and Olhaberry JV. mono-therapy with magnesium increases abnormally low high-density lipoprotein cholesterol: a clinical assay. Current Therapeutic Research. 1984;36:341-346. 
34. Itoh K, Kawasaka T and Nakamura M. The effects of high oral magnesium supplementation on blood pressure, serum lipids and related variables in apparently healthy Japanese subjects. The British journal of nutrition. 1997;78:737-50.

35. Rasmussen HS, Aurup P, Goldstein K, McNair P, Mortensen PB, Larsen OG and Lawaetz H. Influence of magnesium substitution therapy on blood lipid composition in patients with ischemic heart disease. A double-blind, placebo controlled study. Arch Intern Med. 1989;149:1050-3.

36. Barbagallo M, Dominguez L, Galioto A, Ferlisi A, Cani C, Malfa L, Pineo A, Busardo A and Paolisso $\mathrm{G}$. Role of magnesium in insulin action, diabetes and cardio-metabolic syndrome X. Molecular Aspects of Medicine. 2003;24:39-52.

37. Seelig MS and Heggtveit HA. Magnesium interrelationships in ischemic heart disease: a review. The American journal of clinical nutrition. 1974;27:59-79.

38. Touyz RM. Role of magnesium in the pathogenesis of hypertension. Mol Aspects Med. 2003;24:107-36.

39. Chakraborti S, Chakraborti T, Mandal M, Mandal A, Das S and Ghosh S. Protective role of magnesium in cardiovascular diseases: a review. Mol Cell Biochem. 2002;238:163-79.

40. Paolisso $\mathrm{G}$ and Barbagallo $\mathrm{M}$. Hypertension, diabetes mellitus, and insulin resistance: the role of intracellular magnesium. AM J Hypertens. 1997;10:346-355.

41. Shechter M. Does magnesium have a role in the treatment of patients with coronary artery disease? American journal of cardiovascular drugs : drugs, devices, and other interventions. 2003;3:2319.

42. Touyz RM. Magnesium in clinical medicine. Front Biosci. 2004;9:1278-93.

43. Nadler JL, Malayan S, Luong H, Shaw S, Natarajan RD and Rude RK. Intracellular free magnesium deficiency plays a key role in increased platelet reactivity in type II diabetes mellitus. Diabetes care. 1992;15:835-41.

44. Paolisso G, Tirelli A, Coppola L, Verrazzo G, Pizza G, Sgambato S and D'Onofrio F. Magnesium administration reduces platelet hyperaggregability in NIDDM. Diabetes Care. 1989;12:167-8.

45. Pokan R, Hofmann P, von Duvillard SP, Smekal G, Wonisch M, Lettner K, Schmid P, Shechter M, Silver B and Bachl N. Oral magnesium therapy, exercise heart rate, exercise tolerance, and myocardial function in coronary artery disease patients. Br J Sports Med. 2006;40:773-8.

46. Hashimoto T, Hara A, Ohkubo T, Kikuya M, Shintani Y, Metoki H, Inoue R, Asayama K, Kanno A, Nakashita M, Terata S, Obara T, Hirose T, Hoshi H, Totsune K, Satoh H and Imai Y. Serum magnesium, ambulatory blood pressure, and carotid artery alteration: the Ohasama study. American journal of hypertension. 2010;23:1292-8.

47. Ma J, Folsom AR, Melnick SL, Eckfeldt JH, Sharrett AR, Nabulsi AA, Hutchinson RG and Metcalf PA. Associations of serum and dietary magnesium with cardiovascular disease, hypertension, diabetes, insulin, and carotid arterial wall thickness: the ARIC study. Atherosclerosis Risk in Communities Study. Journal of clinical epidemiology. 1995;48:927-40.

48. Peacock JM, Ohira T, Post W, Sotoodehnia N, Rosamond W and Folsom AR. Serum magnesium and risk of sudden cardiac death in the Atherosclerosis Risk in Communities (ARIC) Study. American heart journal. 2010;160:464-70.

49. Maier JA, Nasulewicz-Goldeman A, Simonacci M, Boninsegna A, Mazur A and Wolf FI. Insights into the mechanisms involved in magnesium-dependent inhibition of primary tumor growth. Nutr Cancer. 2007;59:192-8.

50. Tam M, Gomez S, Gonzalez-Gross M and Marcos A. Possible roles of magnesium on the immune system. Eur J Clin Nutr. 2003;57:1193-7.

51. Song Y, Ridker PM, Manson JE, Cook NR, Buring JE and Liu S. Magnesium intake, C-reactive protein, and the prevalence of metabolic syndrome in middle-aged and older U.S. women. Diabetes Care. 2005;28:1438-44. 
52. Dai Q, Shu XO, Deng X, Xiang YB, Li H, Yang G, Shrubsole MJ, Ji B, Cai H, Chow WH, Gao YT and Zheng $\mathrm{W}$. Modifying effect of calcium/magnesium intake ratio and mortality: a population-based cohort study. BMJ Open. 2013;3.

53. Leone $\mathrm{N}$, Courbon $\mathrm{D}$, Ducimetiere $\mathrm{P}$ and Zureik $\mathrm{M}$. Zinc, copper, and magnesium and risks for allcause, cancer, and cardiovascular mortality. Epidemiology (Cambridge, Mass). 2006;17:308-14.

54. Nechifor M, Chelarescu D, Mandreci I and Cartas N. Magnesium influence on nicotine pharmacodependence and smoking. Magnesium research : official organ of the International Society for the Development of Research on Magnesium. 2004;17:176-81.

55. Niemela JE, Cecco SA, Rehak NN and Elin RJ. The effect of smoking on the serum ionized magnesium concentration is method-dependent. Archives of pathology \& laboratory medicine. 1997;121:1087-92.

56. Khand F, Shaikh SS, Ata MA and Shaikh SS. Evaluation of the effect of smoking on complete blood counts, serum C-reactive protein and magnesium levels in healthy adult male smokers. JPMA The Journal of the Pakistan Medical Association. 2015;65:59-61.

57. Li W, Zheng T, Altura BT and Altura BM. Magnesium modulates contractile responses of rat aorta to thiocyanate: A possible relationship to smoking-induced atherosclerosis. Toxicol Appl Pharmacol. 1999;157:77-84.

58. Nechifor M. Magnesium and Zinc Involvement in Tobacco Addiction. Journal of Addiction Research and Therapy. 2012;S2:1-5. 


\section{FIGURES LEGENDS}

FIGURE 1: Weighted histogram of serum Mg levels in 14,353 participants (8,555 Women and 5,798 men) at baseline (1971-1975) for total and by sex and race.

FIGURE 2: Adjusted hazard ratios of all-cause mortality in the US general adults (NHANES I 1971-2011). The solid curve represents for multivariate-adjusted hazard ratios calculated by restricted cubic splines with knots at serum Mg levels of 0.73, 0.82, 0.87, and $0.96 \mathrm{mmol} / \mathrm{L}$. The reference value $(\mathrm{HR}=1)$ was set at serum $\mathrm{Mg}$ levels of $0.80 \mathrm{mmol} / \mathrm{L}$. Hazard ratios were estimated by using weighted Cox regression model adjusted for age, sex, race/ethnicity, education, family income, smoking status, alcohol consumptions, physical activity, BMI, history of diabetes, hypertension, and vitamin and/or mineral supplements use.

FIGURE 3: Multivariate-adjusted hazard ratios (95\% CIs) for all-cause, CVD, and cancer mortality by 7 categories of serum Mg level among women and men.

FIGURE 4: Hazard ratios (95\% CIs) of all-cause, CVD, and cancer mortality stratified by age, race, BMI, recreational physical activity, non-recreational physical activity, diabetes, hypertension, CVD, smoking status, alcohol consumption, and vitamin and/or mineral supplements use. Gray line indicates no increase in mortalities $(\mathrm{HR}=1)$. Error bars indicate 95\% CIs.

* RPA indicates the recreational physical activity, and ** NRPA indicates non-recreational physical activity. 
Table 1. Baseline characteristics by categories of serum Mg levels among population of NHANES I 1971- 1975

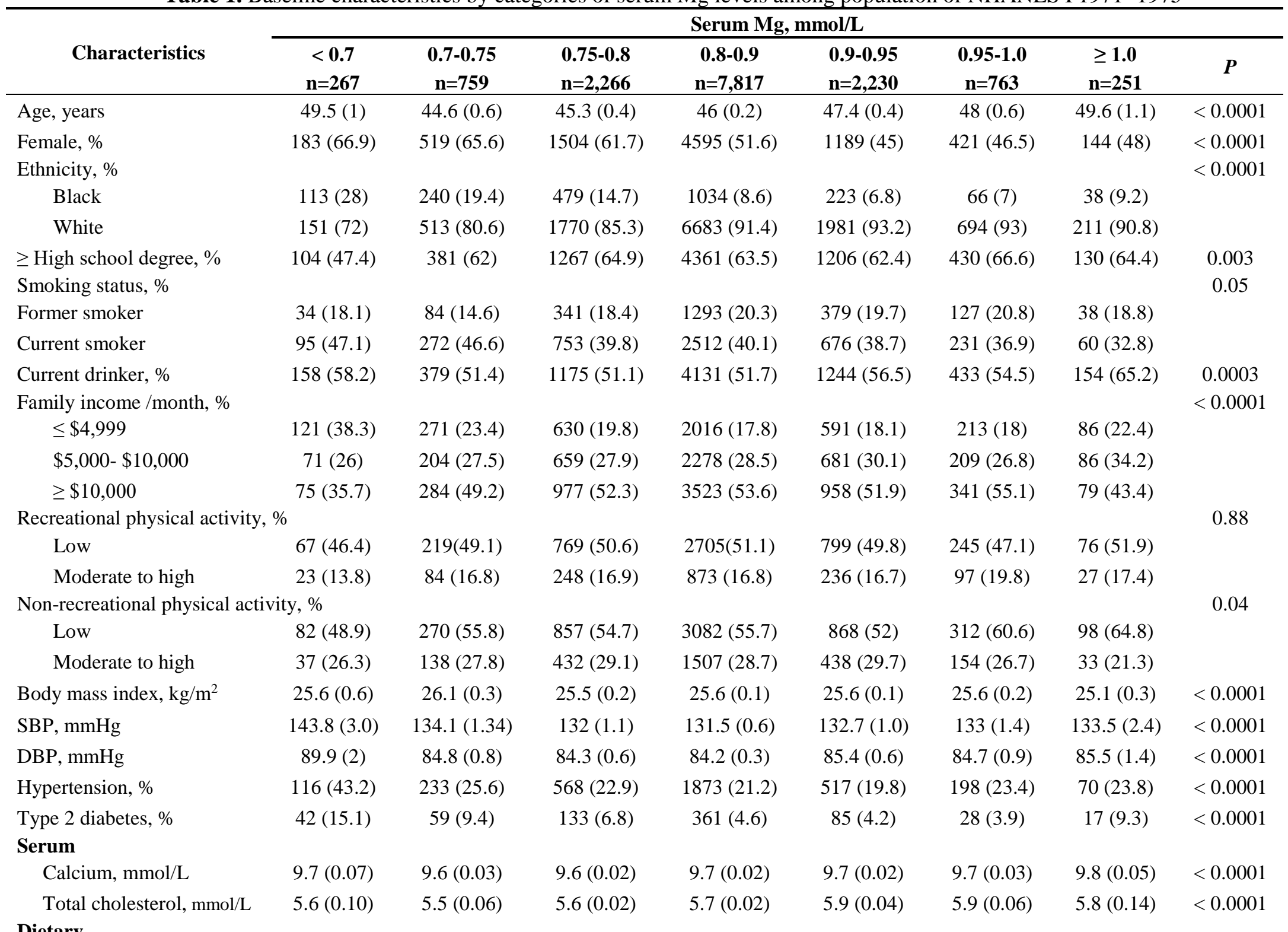


Total energy intake,

$\mathrm{kcal} /$ day

168 (8.1)

$182.3(6.3)$

$179.6(2.7)$

193 (2.1)

197 (3.3)

$187.7(6.4)$

$187(13)$

$<0.0001$

Vitamin/mineral

90 (36.1) 245 (35.3)

732 (32)

$2611(34.3)$

$775(36.1)$

$261(34.5)$

87 (35.1)

$P$ values are presented for linear trend test.

The means (SEs) were calculated for continuous variables, and n (frequency) was presented for categorical variables. 
Table 2. Independent predictors of Mg deficiency (serum $\mathrm{Mg}<0.7 \mathrm{mmol} / \mathrm{L}$ or $0.75 \mathrm{mmol} / \mathrm{L}$ ) among 14,353 adults older than 20 years

\begin{tabular}{lllll}
\hline \multirow{2}{*}{ Characters } & \multicolumn{3}{c}{ Mg deficiency } \\
\cline { 2 - 5 } & \multicolumn{2}{c}{ Mg < 0.70 mmol/L } & \multicolumn{2}{c}{ Mg < 0.75 mmol/L } \\
\cline { 2 - 5 } & OR (95\% CI) & P-value & OR (95\% CI) & P-value \\
\hline Age, per 10 yr & $1.04(0.88,1.23)$ & 0.65 & $0.92(0.83,1.02)$ & 0.11 \\
Female sex & $2.22(1.19,4.13)$ & 0.01 & $1.89(1.43,2.50)$ & $<0.0001$ \\
Race/ethnicity, non-white race & $3.12(1.93,5.05)$ & $<0.0001$ & $2.53(1.98,3.23)$ & $<0.0001$ \\
$\geq$ High school degree & $1.45(0.84,2.49)$ & 0.19 & $1.06(0.82,1.36)$ & 0.68 \\
Family income, per \$5,000/month & $0.86(0.59,1.27)$ & 0.45 & $0.90(0.76,1.06)$ & 0.20 \\
BMI, 25 vs <25 kg/m $\mathbf{m}^{2}$ & $0.69(0.40,1.18)$ & 0.17 & $0.99(0.76,1.28)$ & 0.91 \\
Recreational physical activity & & & & \\
$\quad$ Low & $1.22(0.74,2.03)$ & 0.27 & $1.04(0.81,1.34)$ & 0.74 \\
$\quad$ Moderate to high & $0.85(0.39,1.86)$ & 0.47 & $1.00(0.74,1.37)$ & 0.90 \\
Smoking, vs never smoker & & & & \\
$\quad$ Current smoker & $1.69(0.98,2.94)$ & 0.64 & $1.59(1.19,2.13)$ & 0.02 \\
$\quad$ Former smoker & $2.23(1.02,4.90)$ & 0.14 & $1.39(0.96,2.01)$ & 0.56 \\
Current drinker & $1.22(0.79,1.90)$ & 0.37 & $1.15(0.92,1.45)$ & 0.23 \\
Supplement use, Yes & $1.56(1.02,2.41)$ & 0.04 & $1.17(0.93,1.46)$ & 0.19 \\
Diabetes, Yes & $2.82(1.39,5.73)$ & 0.004 & $2.74(1.61,4.68)$ & 0.0002 \\
CVD, Yes & $0.88(0.38,2.03)$ & 0.76 & $1.07(0.68,1.68)$ & 0.77 \\
Hypertension, Yes & $2.18(1.31,3.63)$ & 0.003 & $1.38(1.00,1.90)$ & 0.05 \\
Total cholesterol, per mg/dL & $0.79(0.63,0.98)$ & 0.04 & $0.84(0.75,0.93)$ & 0.001 \\
\hline
\end{tabular}


Table 3. Mortality rates and adjusted hazard ratios (95\% CIs) of all-cause, cancer, CVDs, CHD, and stroke across the categories of baseline serum Mg concentrations.

\begin{tabular}{|c|c|c|c|c|c|}
\hline $\begin{array}{l}\text { Serum Mg, } \\
\mathrm{mmol} / \mathrm{L}\end{array}$ & $\begin{array}{l}\text { No. of events/ } \\
\text { all participants }\end{array}$ & Mortality $^{\text {a }}$ & $\begin{array}{l}\text { Hazard ratio } \\
(95 \% \text { CI })^{b}\end{array}$ & $\begin{array}{l}\text { Hazard ratio } \\
(95 \% \mathrm{CI})^{c}\end{array}$ & $\begin{array}{l}\text { Hazard ratio } \\
(95 \% \text { CI })^{d}\end{array}$ \\
\hline \multicolumn{6}{|c|}{ All-cause mortality } \\
\hline$<0.7$ & $211 / 267$ & 3343 & $1.69(1.33,2.14)$ & $1.73(1.34,2.22)$ & $1.34(1.02,1.77)^{*}$ \\
\hline $0.7-0.75$ & $470 / 759$ & 1955 & $1.21(1.04,1.41)$ & $0.98(0.80,1.21)$ & $0.94(0.75,1.18)$ \\
\hline $0.75-0.8$ & $1309 / 2266$ & 1959 & $1.14(1.06,1.23)$ & $1.05(0.96,1.16)$ & $1.08(0.97,1.19)$ \\
\hline $0.8-0.9$ & $4828 / 7817$ & 1999 & 1 & 1 & 1 \\
\hline $0.9-0.95$ & $1499 / 2230$ & 2230 & $1.01(0.94,1.08)$ & $1.00(0.91,1.09)$ & $1.05(0.95,1.16)$ \\
\hline $0.95-1.0$ & $523 / 763$ & 2259 & $0.95(0.85,1.08)$ & $0.95(0.83,1.09)$ & $0.96(0.79,1.15)$ \\
\hline$\geq 1.0$ & $172 / 251$ & 2307 & $1.01(0.84,1.21)$ & $0.92(0.74,1.16)$ & $0.98(0.76,1.26)$ \\
\hline \multicolumn{6}{|c|}{ Cancer mortality } \\
\hline$<0.7$ & $36 / 267$ & 592 & $1.36(0.93,1.97)$ & $1.39(0.92,2.11)$ & $1.39(0.83,2.32)$ \\
\hline $0.7-0.75$ & $80 / 759$ & 390 & $1.01(0.73,1.39)$ & $0.88(0.59,1.32)$ & $0.90(0.57,1.44)$ \\
\hline $0.75-0.8$ & $306 / 2266$ & 452 & $1.11(0.94,1.31)$ & $1.09(0.90,1.32)$ & $1.12(0.89,1.42)$ \\
\hline $0.8-0.9$ & $1055 / 7817$ & 464 & 1 & 1 & 1 \\
\hline $0.9-0.95$ & $314 / 2230$ & 529 & $1.05(0.90,1.24)$ & $1.03(0.86,1.25)$ & $1.23(1.01,1.50)^{*}$ \\
\hline $0.95-1.0$ & $104 / 763$ & 480 & $0.91(0.69,1.20)$ & $0.92(0.69,1.24)$ & $0.98(0.71,1.35)$ \\
\hline$\geq 1.0$ & $28 / 251$ & 411 & $0.80(0.50,1.28)$ & $0.49(0.24,0.96)$ & $0.57(0.27,1.22)$ \\
\hline \multicolumn{6}{|c|}{ CVD mortality } \\
\hline$<0.7$ & $88 / 267$ & 1343 & $1.57(1.10,2.22)$ & $1.55(1.02,2.34)$ & $1.28(0.81,2.02)$ \\
\hline $0.7-0.75$ & $217 / 759$ & 855 & $1.29(1.02,1.63)$ & $1.03(0.76,1.41)$ & $0.98(0.70,1.37)$ \\
\hline $0.75-0.8$ & $563 / 2266$ & 835 & $1.18(1.04,1.33)$ & $1.09(0.93,1.28)$ & $1.15(0.95,1.39)$ \\
\hline $0.8-0.9$ & 2076/ 7817 & 832 & 1 & 1 & 1 \\
\hline $0.9-0.95$ & $690 / 2230$ & 978 & $1.04(0.92,1.17)$ & $1.02(0.88,1.18)$ & $1.03(0.86,1.23)$ \\
\hline $0.95-1.0$ & $241 / 763$ & 979 & $0.97(0.81,1.15)$ & $1.00(0.81,1.25)$ & $1.08(0.81,1.44)$ \\
\hline$\geq 1.0$ & $84 / 251$ & 1124 & $1.16(0.89,1.50)$ & $1.25(0.91,1.72)$ & $1.45(1.07,1.96)$ \\
\hline \multicolumn{6}{|c|}{ CHD mortality } \\
\hline$<0.7$ & $53 / 267$ & 758 & $1.58(1.04,2.41)$ & $1.49(0.91,2.43)$ & $1.15(0.64,2.04)$ \\
\hline $0.7-0.75$ & $124 / 759$ & 507 & $1.35(1.00,1.83)$ & $0.95(0.64,1.42)$ & $0.85(0.55,1.34)$ \\
\hline $0.75-0.8$ & $324 / 2266$ & 519 & $1.27(1.07,1.51)$ & $1.10(0.90,1.35)$ & $1.20(0.94,1.53)$ \\
\hline $0.8-0.9$ & $1179 / 7817$ & 485 & 1 & 1 & 1 \\
\hline $0.9-0.95$ & $412 / 2230$ & 589 & $1.06(0.91,1.23)$ & $1.02(0.84,1.23)$ & $1.02(0.80,1.30)$ \\
\hline $0.95-1.0$ & $143 / 763$ & 598 & $1.01(0.81,1.25)$ & $1.03(0.79,1.34)$ & $1.11(0.78,1.59)$ \\
\hline$\geq 1.0$ & $48 / 251$ & 598 & $1.07(0.73,1.57)$ & $1.06(0.65,1.72)$ & $1.29(0.77,2.17)$ \\
\hline \multicolumn{6}{|c|}{ Stroke mortality } \\
\hline $\begin{array}{l}<0.7 \\
0.7-0.75\end{array}$ & $\begin{array}{l}16 / 267 \\
38 / 759\end{array}$ & $\begin{array}{l}287 \\
106\end{array}$ & $\begin{array}{l}1.81(0.92,3.57) \\
0.92(0.58,1.47)\end{array}$ & $\begin{array}{l}2.67(1.31,5.45) \\
0.92(0.51 .168)\end{array}$ & $\begin{array}{l}2.55(1.18,5.48)^{*} \\
0.86(0.47,1.59)\end{array}$ \\
\hline $0.75-0.8$ & 99/ 2266 & 121 & $0.97(0.73,1.29)$ & $1.02(0.70,1.48)$ & $1.01(0.65,1.56)$ \\
\hline $0.8-0.9$ & $379 / 7817$ & 144 & 1 & 1 & 1 \\
\hline $0.9-0.95$ & $107 / 2230$ & 150 & $0.91(0.67,1.24)$ & $0.93(0.65,1.33)$ & $0.92(0.60,1.42)$ \\
\hline $0.95-1.0$ & $52 / 763$ & 222 & $1.27(0.86,1.87)$ & $1.41(0.87,2.28)$ & $1.46(0.85,2.52)$ \\
\hline$\geq 1.0$ & $17 / 251$ & 250 & $1.44(0.79,2.61)$ & $1.58(0.76,3.26)$ & $1.72(0.88,3.38)$ \\
\hline
\end{tabular}


a: The mortalities were calculated as per 100,000 person-years.

b: The HRs (95\% CIs) were calculated based on the model 1: adjusted for age, gender and race; c: The HRs (95\% CIs) were calculated based on the model 2: adjusted for age, gender, race, BMI, physical activity, smoking status, and alcohol consumption;

d: The HRs (95\% CIs) were calculated based on the model 3: adjusted for age, gender, race, BMI, physical activity, education, smoking status, alcohol consumption, history of diabetes, history of hypertension, and vitamin or mineral supplements use. 
Figure 1.
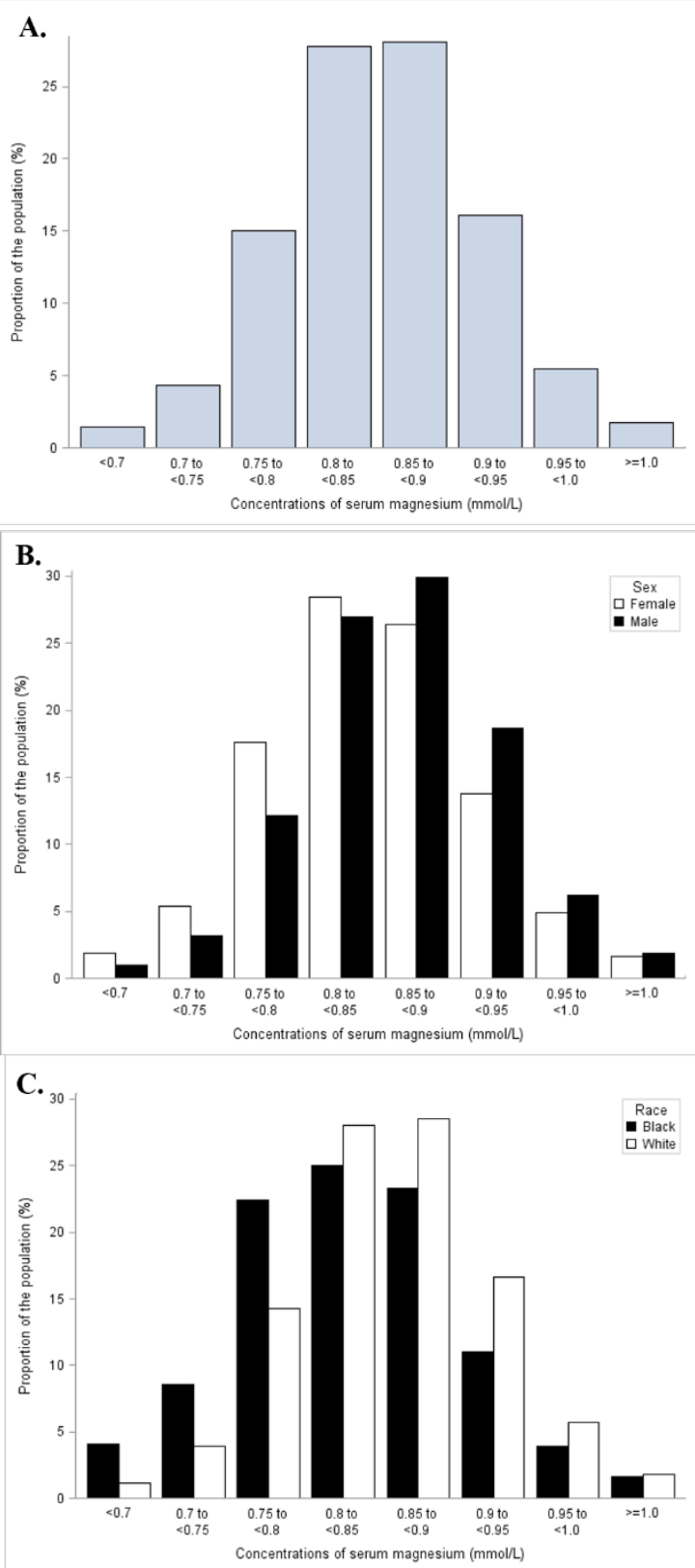
Figure 2.

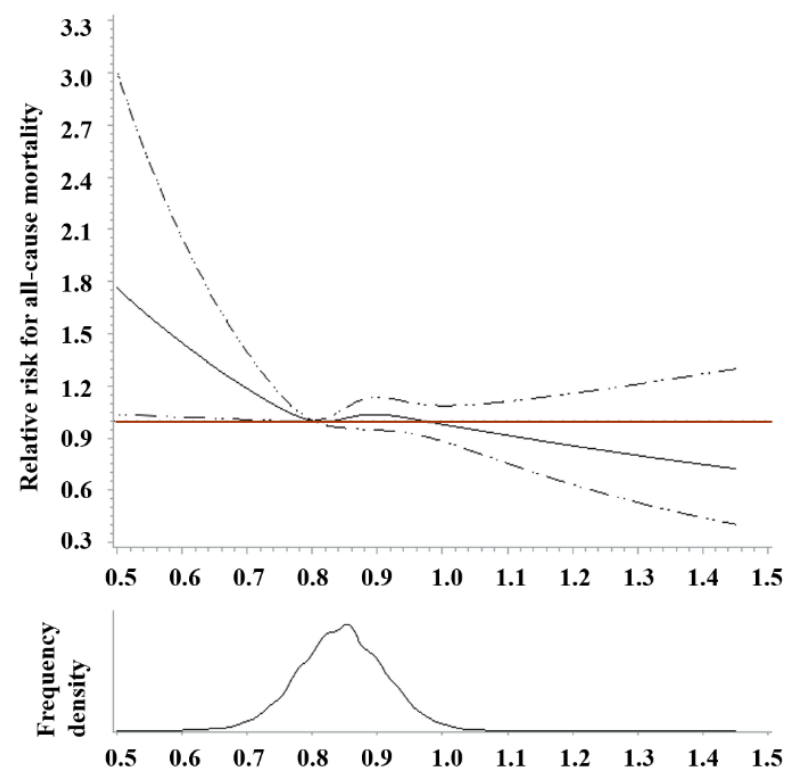


Figure 3.

A.

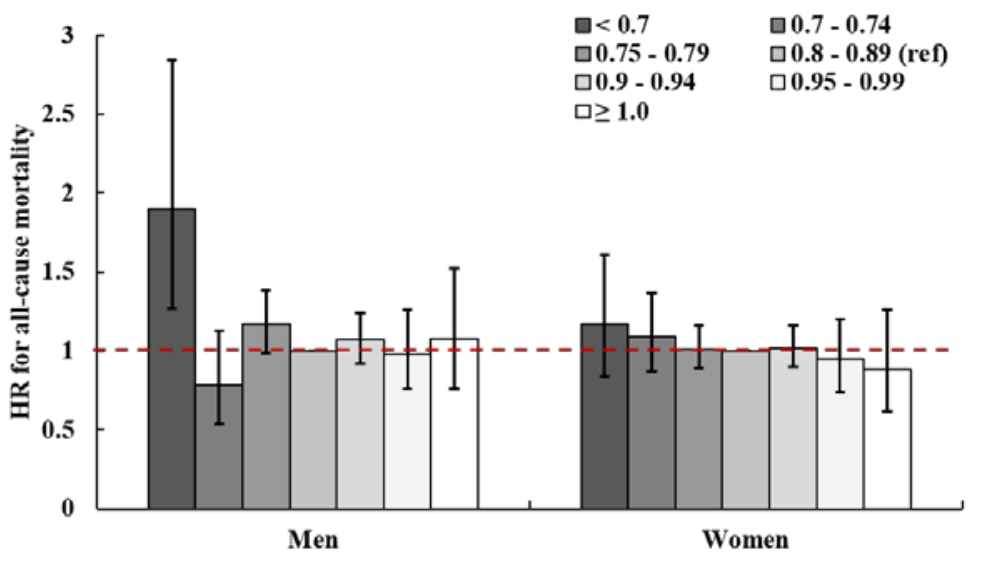

B.

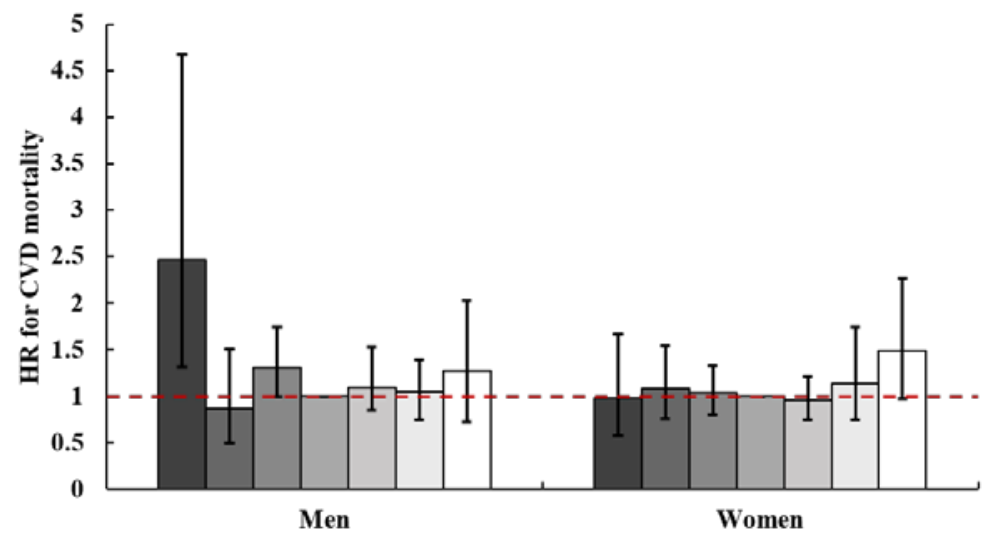

C.

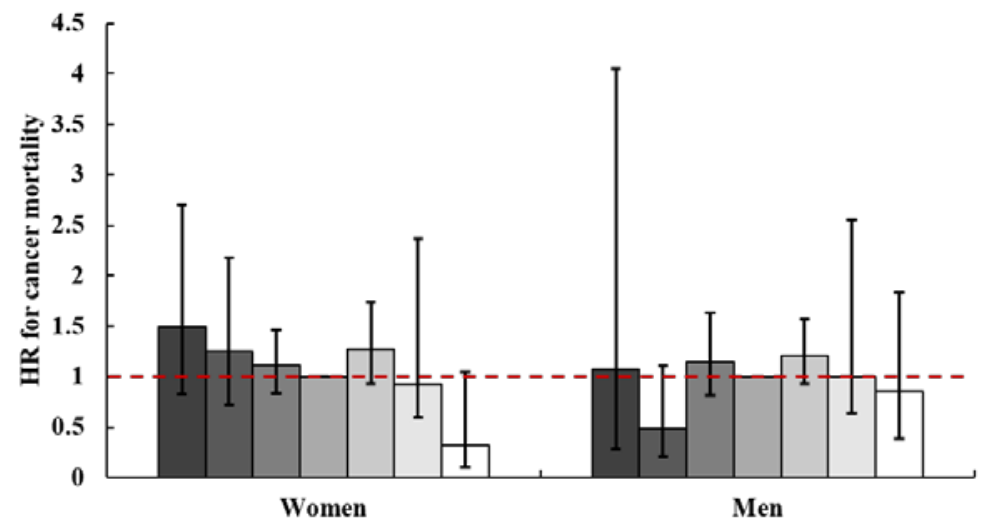


Figure 4.

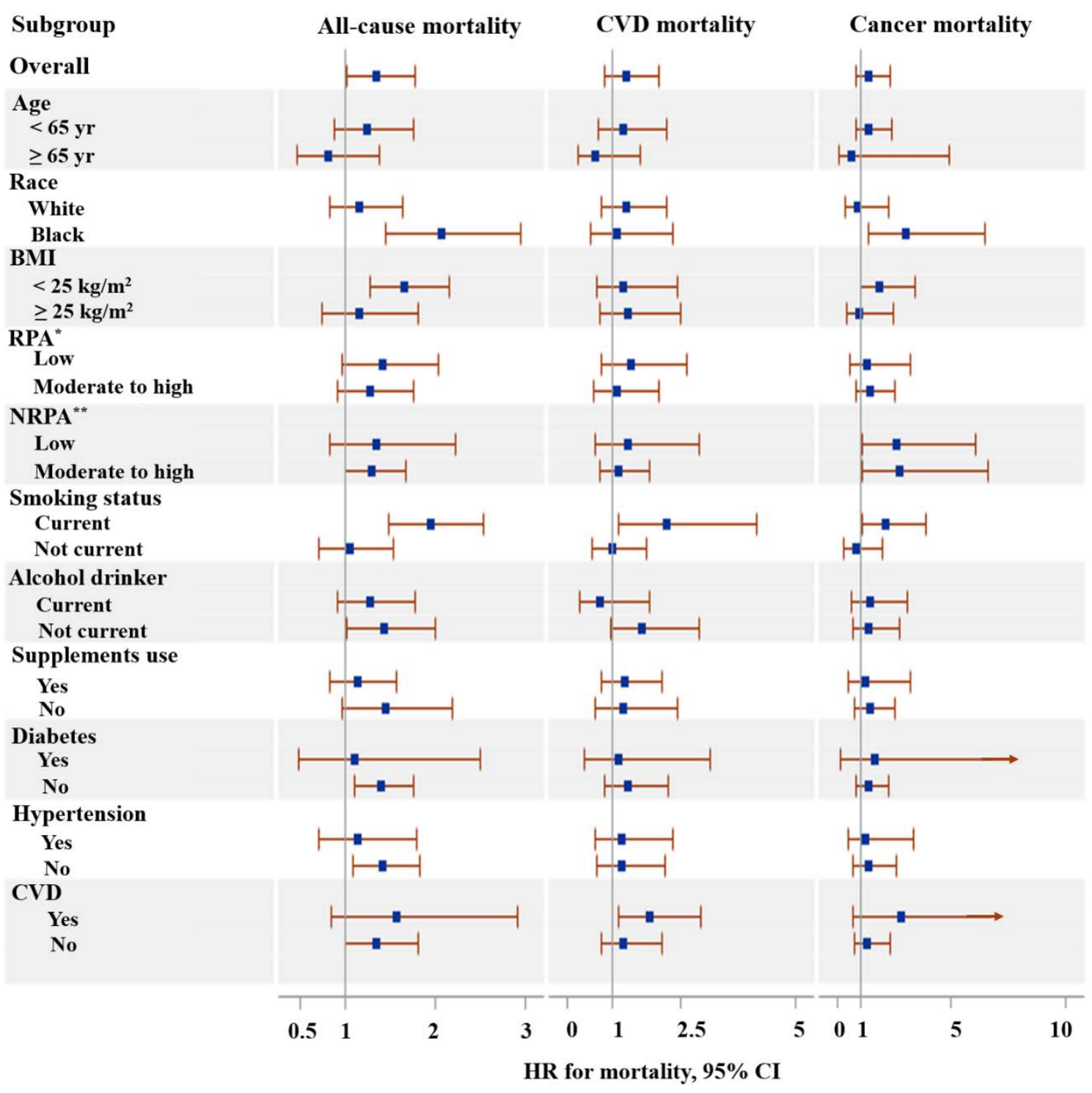

